\title{
Warming but Not Nitrogen Addition Alters the Linear Relationship Between Microbial Respiration and Biomass
}

\author{
Hui Wei', Xiaomei Chen ${ }^{2}$, Jinhong He ${ }^{3,4}$, Letong Huang ${ }^{1}$ and Weijun Shen ${ }^{3 *}$ \\ ${ }^{1}$ Key Laboratory of Agro-Environment in the Tropics, Ministry of Agriculture, South China Agricultural University, Guangzhou,

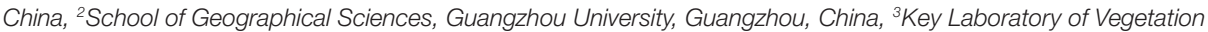 \\ Restoration and Management of Degraded Ecosystems, South China Botanical Garden, Chinese Academy of Sciences, \\ Guangzhou, China, ${ }^{4}$ University of Chinese Academy of Sciences, Beijing, China
}

\section{OPEN ACCESS}

Edited by:

Dagmar Woebken,

University of Vienna, Austria

Reviewed by:

Muhammad Saleem,

Alabama State University,

United States

Jörg Schnecker,

University of Vienna, Austria

*Correspondence:

Weijun Shen

shenweij@scbg.ac.cn

Specialty section:

This article was submitted to

Terrestrial Microbiology,

a section of the journal

Frontiers in Microbiology

Received: 01 September 2018 Accepted: 26 April 2019

Published: 10 May 2019

Citation:

Wei H, Chen X, He J, Huang L and Shen W (2019) Warming but Not Nitrogen Addition Alters the Linear Relationship Between Microbial Respiration and Biomass. Front. Microbiol. 10:1055. doi: 10.3389/fmicb.2019.01055
Soil contains a large amount of organic matter, which constitutes the largest terrestrial carbon pool. Heterotrophic or microbial respiration $\left(R_{h}\right)$ that results from microbial decomposition of soil organic carbon (SOC) constitutes a substantial proportion of soil C efflux. Whether soil microbial biomass is of primary importance in controlling $R_{h}$ remains under debate, and the question of whether the microbial biomass-decomposition relationship changes with warming and nitrogen $(\mathrm{N})$ deposition has rarely been assessed. We conducted an incubation experiment to test the relationship between $R_{h}$ and the size of soil microbial communities in two layers of soil collected from a natural subtropical forest and to examine whether the relationship was affected by changes in temperature and by added $\mathrm{N}$ in different forms. The results showed that regardless of the added $\mathrm{N}$ species, the $\mathrm{N}$ load did not significantly affect $\mathrm{R}_{\mathrm{h}}$ or the size of the soil microbial communities. These results could be due to a long-term $\mathrm{N}$-rich soil condition that acclimates soil microbial communities to resist $\mathrm{N}$ inputs into the studied forest; however, warming may significantly stimulate SOC decomposition, reducing soil microbial biomass under high temperatures. A significant linear soil microbial biomass-decomposition relationship was observed in our study, with the coefficients of determination ranging from 54 to $70 \%$. Temperature rather than $\mathrm{N}$ additions significantly modified the linear relationship between soil microbial biomass and respiration. These results suggest that warming could impose a more substantial impact than $\mathrm{N}$ addition on the relationship between soil microbial biomass and SOC decomposition.

Keywords: heterotrophic soil respiration, soil organic matter decomposition, warming, atmospheric $\mathrm{N}$ deposition, subtropical forest

\section{INTRODUCTION}

In the terrestrial biosphere, soil reserves the greatest amount of carbon (C), with top soil to a depth of $1 \mathrm{~m}$ contributing approximately two-thirds (approximately 1,500 Pg) of the global C stock (Batjes, 1996; Scharlemann et al., 2014; Lal, 2018). The size of the soil C pool is even larger than that of the combined biotic and atmospheric $\mathrm{C}$ pools. Stabilizing such a 
large $\mathrm{C}$ pool is critical to balancing the global $\mathrm{C}$ cycle and stabilizing the global climate system (Friedlingstein et al., 2010; Melillo et al., 2017); therefore, many attempts have been made to study topics related to soil organic carbon (SOC), e.g., quantifying the global and regional $\mathrm{C}$ stocks, exploring the key influential factors, and predicting SOC dynamics under global changes.

Soil, as the largest terrestrial $\mathrm{C}$ pool, emits approximately $100 \mathrm{Pg} \mathrm{CO}_{2}-\mathrm{C}$ into the atmosphere per year (Bond-Lamberty and Thomson, 2010; Jian et al., 2018), primarily through the microbial SOC decomposition that constitutes $\sim 63 \%$ of global soil respiration (Bond-Lamberty et al., 2018). The decomposition of SOC, which has often been used interchangeably with heterotrophic respiration in the literature (Kirschbaum, 2006), greatly influences the stock of soil $\mathrm{C}$ and its feedback to climate (Stewart et al., 2007; Bond-Lamberty et al., 2018). Temperature and moisture are of primary importance for determining the rate of SOC decomposition in most ecosystems, since they directly affect the size and activity of SOC decomposers. Moreover, temperature and moisture can regulate multiple processes, such as the absorption of enzymes and SOC on the soil surface, indirectly affecting SOC decomposition (Davidson and Janssens, 2006; Conant et al., 2011; Zhou et al., 2014). Soil texture (especially clay content) and substrate availability are frequently advanced as controlling factors of SOC decomposition and have therefore received considerable attention (Wang et al., 2003; von Lützow et al., 2006; Birge et al., 2015). As direct decomposition agents, soil microbial communities are recognized as likely playing critical roles in SOC decomposition by adjusting the community size, composition, and function in changing habitats (Ramirez et al., 2012; Whitaker et al., 2014; Huang et al., 2018).

However, the relationship between decomposition and the soil microbial community size (hereafter abbreviated as the decomposition-biomass relationship) remains inconclusive, with limited and contradictory observations (Stockmann et al., 2013; Saleem, 2015). For instance, Ramirez et al. (2012) observed that SOC decomposition was altered less than soil microbial biomass (on average -11 vs. $-35 \%$ ) over a 1-year-long soil incubation with $\mathrm{N}$ additions and Liu and Greaver (2010) found a similar pattern from a global perspective ( -8 vs. $-20 \%)$. These results suggest that $\mathrm{N}$ deposition could change the decomposition-biomass relationship. Moreover, a recent study showed that SOC decomposition and the total amount of microbial phospholipid fatty acids (PLFAs) responded differently to the added $\mathrm{N}$ load (Chen et al., 2019), implying that changing $\mathrm{N}$ deposition could affect the decomposition-biomass relationship. While the size of soil microbial communities has been regarded as a main predictor of the SOC decomposition rate (Colman and Schimel, 2013; Garcia-Palacios et al., 2015; Ali et al., 2018) and explicitly presenting its dynamics may improve the predictive performance of soil C models (Hararuk et al., 2015), some authors argue that its inclusion in biogeochemical models is less important (Wang et al., 2003; Birge et al., 2015). Obviously, this variation in the decomposition-biomass relationship impedes a consistent conclusion.

Global warming and atmospheric $\mathrm{N}$ deposition are among the primary issues of global change (Galloway et al., 2008;
Gutknecht et al., 2012; IPCC, 2013), and their ecological consequences still need to be addressed. In spite of the debate over potential mechanisms (e.g., changes in substrate supply vs. microbial acclimation), it is almost a consensus that SOC decomposition can be stimulated by warming temperatures over a short period of time and then return to its previous level after a certain duration of warming. In many cases, soil microbial biomass has been observed to decrease under warming conditions relative to control treatments. These observations imply that warming can modify the decomposition-biomass relationship, but empirical evidence is still needed. Previous studies demonstrate that atmospheric $\mathrm{N}$ deposition can positively, negatively, or not affect SOC decomposition in different ecosystems, with the responses controlled by other factors (such as soil substrate supply and forest productivity) (Janssens et al., 2010; Eberwein et al., 2015; Chen et al., 2019). Compared with the increasing atmospheric $\mathrm{N}$ load, changes in the deposited $\mathrm{N}$ species have received little attention, although they have been widely observed (Liu et al., 2013; Hunova et al., 2017). Furthermore, warming and $\mathrm{N}$ deposition may interactively affect SOC decomposition (Eberwein et al., 2017; Fang et al., 2018), and the response of SOC decomposition to $\mathrm{N}$ deposition likely depends on the input $\mathrm{N}$ species (Wang et al., 2018). However, whether the microbial biomassdecomposition relationship would change with warming and $\mathrm{N}$ deposition has rarely been assessed.

In the present study, temperature and $\mathrm{N}$ species were considered as two treatment factors, and their main and interactive effects on SOC decomposition and the potential decomposition-biomass relationship were observed. Soil samples were collected from surface and subsurface layers in an old-growth evergreen broadleaved forest and incubated. In nature, the upper soil layers are firstly affected by atmospheric environmental changes compared to deep soils. Although experimentally incubating soils in the lab presents potential limitations, two soils that had different properties were considered to be two contrasting treatments and were used to observe the soil microbial response to determine the effects of the initial soil properties. We expected a linear relationship to exist between the soil microbial decomposition and community size in both soils considering that soil microorganisms are the final decomposers of SOC. Temperature and $\mathrm{N}$ species were included as two treatment factors, mainly to clarify whether these important environmental changes altered the decompositionbiomass relationship in soils.

\section{MATERIALS AND METHODS}

\section{Experimental Design}

The studied soils were collected at two soil depths (0-10 and $10-20 \mathrm{~cm}$ ) from a mature forest located in the Dinghushan Nature Reserve $\left(112^{\circ} 30^{\prime} 39^{\prime \prime}-112^{\circ} 33^{\prime} 41^{\prime \prime} \mathrm{E}, 23^{\circ} 09^{\prime} 21^{\prime \prime}-23^{\circ} 11^{\prime} 30^{\prime \prime} \mathrm{N}\right)$ in southern China. The study site has a tropical monsoon climate zone with typical hot rainy and cold dry seasons. The mean annual air temperature is $22.3^{\circ} \mathrm{C}$, and average annual precipitation is approximately $1,600 \mathrm{~mm}$, of which nearly $80 \%$ 
occurs in the hot rainy season from April to September and the remainder in the cold dry season. The studied forest is a climax forest that has naturally developed over 400 years with few anthropogenic disturbances. Evergreen broadleaved tree species, such as Castanopsis chinensis, Schima superba, and Cryptocarya chinensis, are the dominant species. The soil is categorized as an oxisol according to the USDA soil taxonomy (Tang et al., 2006). The surface and subsurface soils that were collected for use in this study had significantly different soil physiochemical and microbial properties, with the surface soil possessing a lower $\mathrm{pH}$ but a substantially higher soil microbial biomass and nutrient concentrations than the subsurface soil (Wei et al., 2017). The two layers of soil were considered to be two soil types of contrasting soil properties for the purpose of determining the treatment effects of warming and $\mathrm{N}$ addition across soils, which would indicate whether the treatment effects change as soil properties changed.

This incubation experiment had a three-factor full factorial design, with soil type, incubation temperature, and $\mathrm{N}$ form as the three independent variables. In particular, two soils (the surface and sub-surface soils), three incubation temperatures $\left(10,20\right.$, and $30^{\circ} \mathrm{C}$ ), and four forms of $\mathrm{N}$ (control with no $\mathrm{N}$ addition, nitrate $\mathrm{N}$, ammonium $\mathrm{N}$, and urea $\mathrm{N}$ ) were employed, producing a total of 24 combinations of experimental treatments. For each treatment, four composite soils collected in each of four $15 \mathrm{~m} \times 15 \mathrm{~m}$ quadrats were treated as four replicates in the incubation and statistical analyses. The incubation temperatures fell within the seasonal temperature range at the study site $\left(3.2-36.5^{\circ} \mathrm{C}\right.$; Wei et al., 2015). $\mathrm{N}$ addition was applied at $3.79 \mathrm{mg} \mathrm{N} 50 \mathrm{~g}^{-1}$ dry soil, approximately equivalent to that of the regional $\mathrm{N}$ deposition load (50 $\mathrm{kg} \mathrm{N} \mathrm{ha}^{-1} \mathrm{y}^{-1}$; Fang et al., 2008). Further information regarding the experimental design can be found in a recent parallel study by Wei et al. (2017).

\section{Incubation Experiment and Sample Analyses}

After collection, the composited soil samples were immediately transferred to the laboratory and mixed by passing through a $2 \mathrm{~mm}$ soil sieve. Visible plant residue and rocks were removed in this pretreatment process. Based on the aforementioned experimental design ( 2 soils $\times 3$ incubation temperatures $\times$ $4 \mathrm{~N}$ forms $\times 4$ replicates), a total of 96 fresh soil samples were prepared. Samples of $50 \mathrm{~g}$ oven-dried-base soils were placed into a $200 \mathrm{~mL}$ triangular glass flask to incubate for 90 days. Three thermostat incubators (RXZ-600B, Southeast Instrument Co., Ltd., Ningbo, China) were set up at the three incubation temperatures. The soil water content within the incubation period was maintained at $55 \%$ of the water holding capacity by adding deionized water after periodically weighing the containers to determine water loss. This level of soil moisture falls within the optimal moisture range for the soil microbial activities in the studied forest (Zhou et al., 2014). Soils were aerobically incubated with a ball of cotton plugging the flasks to minimize water loss while permitting gas exchange.

The soil $\mathrm{CO}_{2}$ efflux rate was measured 12 times over the 90-day incubation period. For each measurement, a rubber stopper was used to seal each flask and two headspace gas samples were collected with $30 \mathrm{~min}$ separating the two collections. The gas samples were immediately analyzed to determine the $\mathrm{CO}_{2}$ concentration on an Agilent $7890 \mathrm{~A}$ gas chromatograph with a flame ionization detector (Agilent Technologies Inc., Palo Alto, California, USA), and increases in the $\mathrm{CO}_{2}$ concentration over time were used to estimate the soil $\mathrm{CO}_{2}$ efflux rate.

At the end of incubation, the soil microbial biomass of each sample was determined using two methods, the chloroform fumigation method and the PLFAs method. In brief, the chloroform fumigation and extraction method were conducted as proposed by Vance et al. (1987), and the C concentration in the extracts was determined on a Total Organic Carbon Analyzer (TOC-VCSH, Shimadzu Corp., Kyoto, Japan) with an extraction efficiency coefficient of 0.45 (Wu et al., 1990). PLFAs were isolated from soil samples as described by Bossio and Scow (1998), with a mixture of chloroform, methanol, and citrate as the buffering solution. Phospholipids were collected using a silica column (500 mg, ANPEL Laboratory Technologies Inc., Shanghai, China), and then, the total amount of PLFAs in each sample was determined using an Agilent 7890 gas chromatograph equipped with a Sherlock Microbial Identification system (version 6.2, MIDI Inc., Newark, Delaware, USA) after methanolysis by adding a mildly alkaline solution. An internal standard fatty acid (19:0) was mixed into each sample to quantify the content of each PLFA, and the sum of the contents of all the PLFAs was determined as the total amount of PLFAs $\left(\mathrm{nmol} \mathrm{\textrm {g } ^ { - 1 }}\right.$ ) for each sample.

\section{Data Analyses}

An integrating method was used to calculate the amount of $\mathrm{CO}_{2}$ emissions during the experimental period (Wetterstedt et al., 2009). Tests of normality were conducted using the Shapiro-Wilk method. Original data were used for further analyses if the normality assumption was met; otherwise, data were rank transformed to obtain normal scores for subsequent analyses. Three-way analyses of variance (ANOVA) were conducted to detect the main and interactive effects of soil, incubation temperature, and $\mathrm{N}$ addition on soil $\mathrm{CO}_{2}$ emission or microbial biomass. One-way ANOVAs were employed to test the significant effects of $\mathrm{N}$ treatments. Due to the nonsignificant $\mathrm{N}$ effects observed in most of the treatment combinations (Tables 1 and 2), we did not categorize samples based on the $\mathrm{N}$ treatments for subsequent analyses. The effects of the incubation temperature were tested by one-way ANOVAs, while those of the soil type were detected using an independentsample $T$ test. Linear regression was conducted to verify the relationships between the two methods of soil microbial biomass or between soil $\mathrm{CO}_{2}$ emission and microbial biomass. Partial correlation analysis was used to double check the significance of the relationship between SOC decomposition and microbial biomass, with the SOC content serving as a controlling factor. The significance level was set at $p \leq 0.05$. All analyses were conducted using IBM SPSS Statistics 22 (IBM Corp., New York, USA), and graphs were made with SigmaPlot 10.0 (Systat Software Inc., California, USA). 
TABLE 1 | Statistical $F$ and significance level $p$ derived from three-way analyses of variances with the incubation temperature (T), nitrogen addition (N), and soil (S) as the three independent factors.

\begin{tabular}{|c|c|c|c|c|c|c|c|c|}
\hline & \multicolumn{2}{|c|}{$\mathrm{CO}_{2}$ emission } & \multicolumn{2}{|c|}{ MBC } & \multicolumn{2}{|c|}{ PLFAs } & \multicolumn{2}{|c|}{$\mathrm{CO}_{2} /$ PLFAs } \\
\hline & $F$ & $p$ & $F$ & $p$ & $F$ & $p$ & $F$ & $p$ \\
\hline $\mathrm{T}$ & 163.97 & $<0.001$ & 20.58 & $<0.001$ & 10.11 & $<0.001$ & 106.32 & $<0.001$ \\
\hline $\mathrm{N}$ & 2.29 & 0.085 & 1.91 & 0.135 & 0.31 & 0.818 & 1.01 & 0.394 \\
\hline$S$ & 144.69 & $<0.001$ & 124.32 & $<0.001$ & 156.71 & $<0.001$ & 2.89 & 0.094 \\
\hline $\mathrm{T} \times \mathrm{N}$ & 1.11 & 0.367 & 2.69 & 0.021 & 0.15 & 0.988 & 0.58 & 0.743 \\
\hline $\mathrm{T} \times \mathrm{S}$ & 3.51 & 0.035 & 5.58 & 0.006 & 1.35 & 0.265 & 6.86 & 0.002 \\
\hline $\mathrm{N} \times \mathrm{S}$ & 0.79 & 0.506 & 1.34 & 0.270 & 0.06 & 0.982 & 0.12 & 0.946 \\
\hline $\mathrm{T} \times \mathrm{N} \times \mathrm{S}$ & 2.20 & 0.053 & 1.61 & 0.158 & 0.10 & 0.996 & 0.093 & 0.997 \\
\hline
\end{tabular}

MBC, microbial biomass carbon; PLFAs, the total amount of phospholipid fatty acids; $\mathrm{CO}_{2} / P L F A s$, the $\mathrm{CO}_{2}$ emissions standardized by PLFAs ( $\mu$ g nmol-1 PLFAs).

TABLE 2 | Statistical $F$ and significance level $p$ derived from one-way analyses of variances with nitrogen addition as the independent factor.

\begin{tabular}{|c|c|c|c|c|c|c|c|c|c|}
\hline \multirow[t]{2}{*}{$\begin{array}{l}\text { Temp. } \\
\left({ }^{\circ} \mathbf{C}\right)\end{array}$} & \multirow{2}{*}{$\begin{array}{l}\text { Soil } \\
\text { layer } \\
(\mathbf{c m})\end{array}$} & \multicolumn{2}{|c|}{$\begin{array}{c}\mathrm{CO}_{2} \\
\text { emission }\end{array}$} & \multicolumn{2}{|c|}{ MBC } & \multicolumn{2}{|c|}{ PLFAs } & \multicolumn{2}{|c|}{$\mathrm{CO}_{2} /$ PLFAs } \\
\hline & & $F$ & $p$ & $F$ & $p$ & $F$ & $p$ & $\boldsymbol{F}$ & $p$ \\
\hline \multirow[t]{2}{*}{10} & $0-10$ & 2.89 & 0.080 & 1.61 & 0.238 & 0.018 & 0.996 & 10.27 & 0.001 \\
\hline & $10-20$ & 1.64 & 0.233 & 4.03 & 0.034 & 0.039 & 0.989 & 0.79 & 0.524 \\
\hline \multirow[t]{2}{*}{20} & $0-10$ & 0.25 & 0.857 & 1.08 & 0.396 & 0.57 & 0.645 & 2.32 & 0.127 \\
\hline & 10-20 & 0.91 & 0.466 & 5.12 & 0.017 & 0.054 & 0.982 & 0.40 & 0.756 \\
\hline \multirow[t]{2}{*}{30} & $0-10$ & 0.17 & 0.916 & 1.45 & 0.277 & 0.12 & 0.949 & 0.47 & 0.710 \\
\hline & 10-20 & 0.12 & 0.945 & 2.50 & 0.109 & 0.28 & 0.842 & 0.26 & 0.854 \\
\hline
\end{tabular}

MBC, microbial biomass carbon; PLFAs, the total amount of phospholipid fatty acids;

$\mathrm{CO}_{2} /$ PLFAs, $\mathrm{CO}_{2}$ emissions standardized by PLFAs ( $\mu \mathrm{g} \mathrm{nmol}{ }^{-1}$ PLFAs).

\section{RESULTS}

Three-way ANOVAs showed that the incubation temperature and soil type had significant effects on the accumulated $\mathrm{CO}_{2}$ emissions, MBC, and total amount of PLFAs $(p<0.001$ for all), while $\mathrm{N}$ addition, regardless of the applied forms, did not significantly affect the soil $\mathrm{CO}_{2}$ emissions and microbial biomass as indicated by MBC and PLFAs ( $p>0.05$; Table 1). The interactive effects between two of the three factors (i.e., temperature, $\mathrm{N}$ form, and soil type) had mostly nonsignificant effects on the accumulated $\mathrm{CO}_{2}$ emissions, $\mathrm{MBC}$, or PLFAs, with exception of the interaction of temperature and soil type on $\mathrm{CO}_{2}$ emissions $(p=0.035)$ and that of temperature and $\mathrm{N}$ addition or soil type on soil MBC ( $p=0.021$ and 0.006 , respectively; Table 1). To further verify the nonsignificant $\mathrm{N}$ effects, one-way ANOVAs were conducted to compare the group means of the accumulated soil $\mathrm{CO}_{2}$ emissions and microbial biomass at each of the three temperatures in one of the two soils (Table 2). The results showed that the $\mathrm{N}$ additions did not significantly alter the accumulated soil $\mathrm{CO}_{2}$ emissions and microbial biomass in most cases $(p>0.05)$, except for $\mathrm{MBC}$ in the subsurface soil at 10 and $20^{\circ} \mathrm{C}(p=0.034$ and 0.017 , respectively; Table 2 ). We further standardized the $\mathrm{CO}_{2}$ emissions by the amount of soil microbial PLFAs to indicate the relative microbial activity per unit of soil microbial biomass. The resultant index of $\mathrm{CO}_{2}$ /PLFAs showed a similar pattern with the total $\mathrm{CO}_{2}$ emissions (Tables 1 and 2).

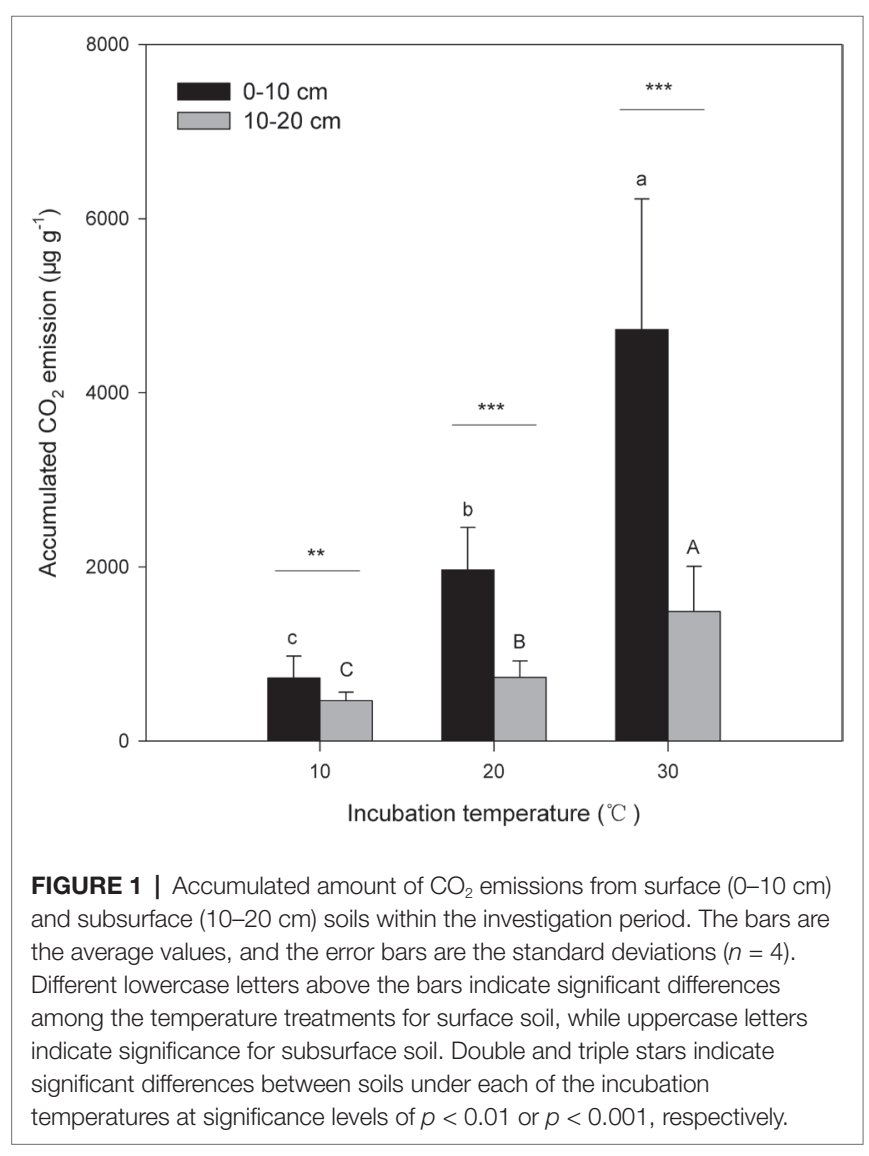

Under the three incubation temperatures, accumulated $\mathrm{CO}_{2}$ emissions were consistently higher from the surface soil than from the subsurface soil within the incubation period, and the surface soil $\mathrm{CO}_{2}$ emissions responded at a greater magnitude to the increasing incubation temperature $(p=0.035$; Table 1; Figure 1). There were significant exponential increases in accumulated soil $\mathrm{CO}_{2}$ emissions in both soils as the incubation temperature increased $(p<0.05$; Figure 1). Likewise, we observed significant differences in soil microbial biomass between the surface and subsurface soils, which were indicated by the consistent pattern of the soil MBC content and total amount of PLFAs between the two soils $(p<0.05$; Figure 2$)$. 

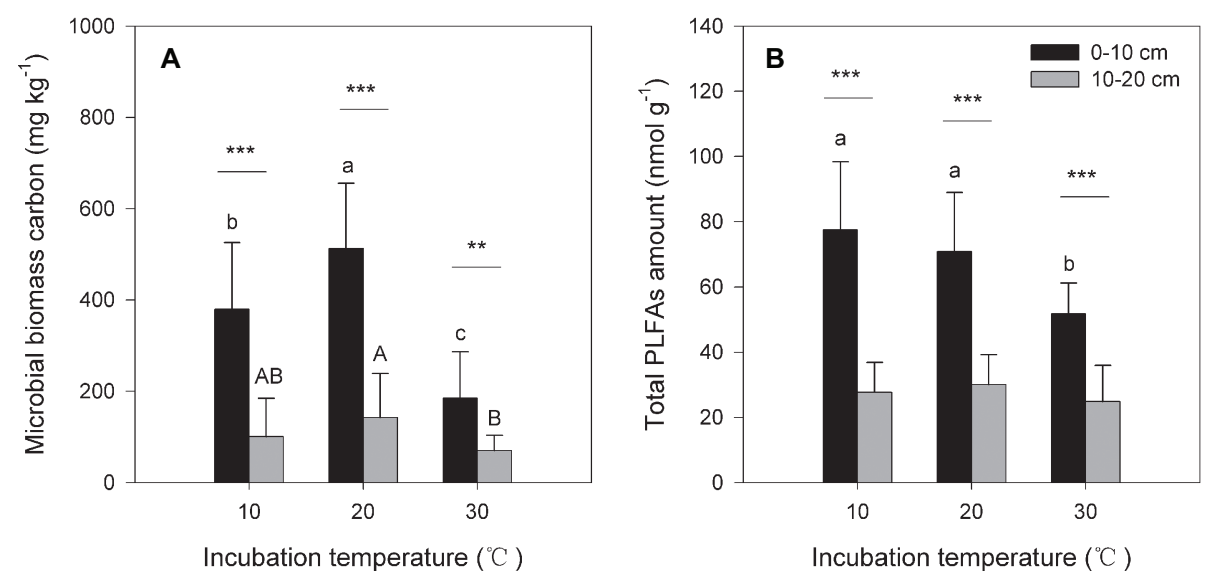

FIGURE 2 | Soil microbial biomass carbon [MBC (A)] and total amount of phospholipid fatty acids [PLFAs (B)] under different incubation temperatures. The bars are the average values, and the error bars are the standard deviations $(n=4)$. Different lowercase letters above the bars indicate significant differences among the temperature treatments for surface soil, while uppercase letters indicate significance for subsurface soil. Double and triple stars indicate significant differences between the soils under each of the incubation temperatures at significance levels of $p<0.01$ or $p<0.001$, respectively.

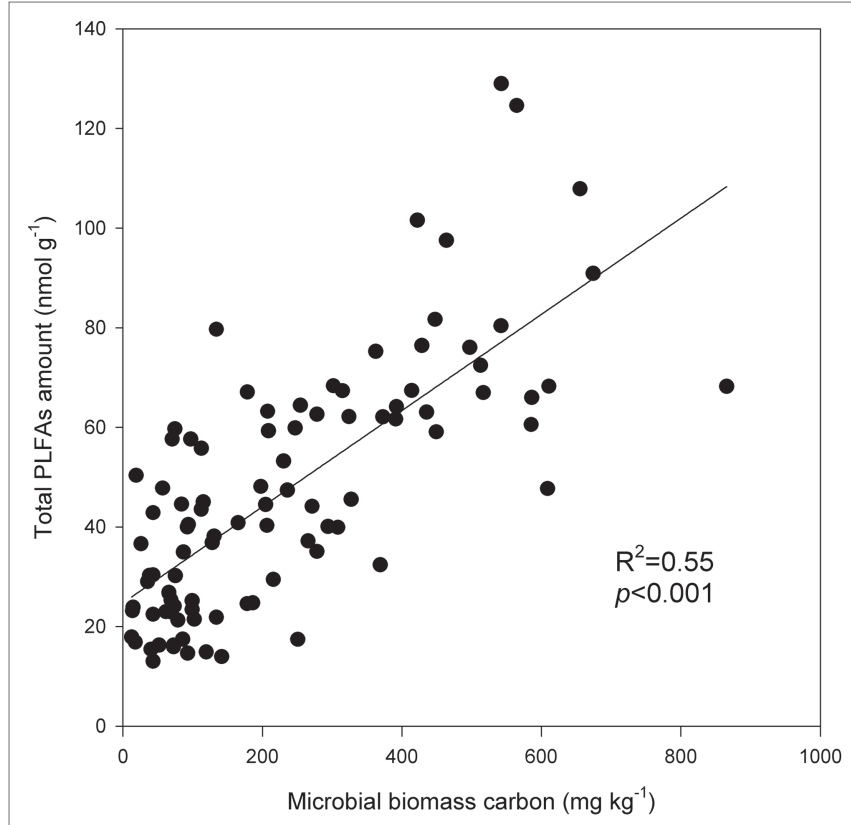

FIGURE 3 | Linear relationship between the total amounts of phospholipid fatty acids (PLFAs) and soil microbial biomass carbon. The plots are observation values, and the solid line is the linear regression line. The coefficient of determination $R^{2}$ and significance level $p$ are presented.

Contrary to the soil $\mathrm{CO}_{2}$ emissions, soil microbial biomass was significantly lower at the higher incubation temperature (i.e., $30^{\circ} \mathrm{C}$ ) than at 10 or $20^{\circ} \mathrm{C}$ in the two soils $(p<0.05)$, except for a case in the subsurface soil that contained a comparable amount of total PLFAs at all three temperatures ( $p>0.05$; Figure 2B). Moreover, the soil MBC content had a significant linear relationship with the total amount of PLFAs ( $p<0.001$; Figure 3), mutually verifying the reliability of the two methods to determine soil microbial biomass.
We conducted linear regressions to detect bivariate correlations between soil $\mathrm{CO}_{2}$ emissions and microbial biomass across soils. The results showed that soil microbial biomass was significantly positively correlated with the accumulated soil $\mathrm{CO}_{2}$ emissions ( $p<0.001$ for all cases; Figure 4). The coefficient of determination of these linear regressions ranged between 0.54 and 0.70 for the MBC content and between 0.57 and 0.69 for PLFAs, suggesting that changes in soil microbial biomass may explain most of the total variation in soil $\mathrm{CO}_{2}$ emissions across soils. This pattern was further verified by the significant correlations between SOC decomposition and MBC or total PLFAs in the partial correlation analyses, where the SOC content served as a control to exclude the interactive effect of the SOC content (indicating substrate supply) on its decomposition $(p<0.05$ for all). Incubation temperature significantly modified the slope of these linear regressions between the accumulated soil $\mathrm{CO}_{2}$ emissions and microbial biomass ( $p<0.001$; Figures 4A,B), and the slope index exponentially increased as the incubation temperature increased $(p<0.001$; Figures 4A1,B1). This pattern was consistent for the two indicators of soil microbial biomass, MBC, and PLFAs (Figures 4A,B).

\section{DISCUSSION}

In the present study, $\mathrm{N}$ additions did not significantly alter the size and activity of soil microbial communities (Tables 1 and 2). This result may be attributable to the N-rich soil conditions of the study site and long-term high $\mathrm{N}$ deposition (Fang et al., 2008; Chen et al., 2015) that causes soil microbial communities to acclimate to $\mathrm{N}$-rich soil conditions. We observed that the soil microbial PLFAs composition was not significantly altered by these types of $\mathrm{N}$ addition in our parallel study (Wei et al., 2017), suggesting microbial resistance to current $\mathrm{N}$ deposition in N-rich forest soils; however, increasing atmospheric $\mathrm{N}$ deposition (Liu et al., 2013) could result in significant 


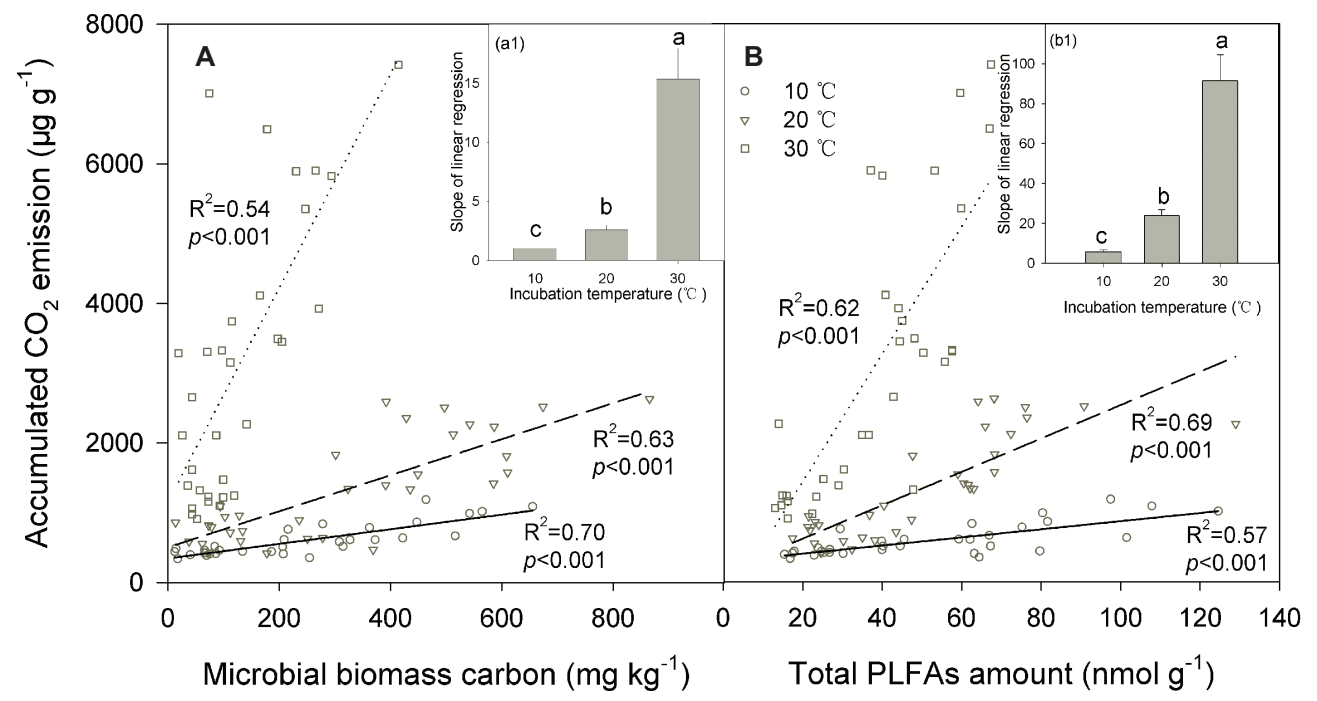

FIGURE 4 | Linear relationship between the accumulated amount of soil $\mathrm{CO}_{2}$ emissions and microbial biomass carbon (A) and the total amount of phospholipid fatty acids [PLFAs (B)] under different incubation temperatures, with the inserted panels A1 and B1 presenting the slopes of linear regressions under the three incubation temperatures. In the figure, the solid lines are regression lines between the two variables observed at $10^{\circ} \mathrm{C}$, while the dashed and potted lines are those at 20 and $30^{\circ} \mathrm{C}$, respectively. The coefficient of determination $R^{2}$ and significance level $p$ are presented for each incubation temperature. Different lowercase letters above the bars in the inserted panels $\mathrm{A} 1$ and $\mathrm{B} 1$ indicate significant differences among the temperatures.

changes in soil microbial communities because soil microorganisms could nonlinearly respond to $\mathrm{N}$ addition, with a $\mathrm{N}$ load threshold above which $\mathrm{N}$ addition will significantly affect soil microbial activity and size (Zhou et al., 2012). This threshold, however, may be context specific. For example, Ramirez et al. (2010) found that soil microbes in a variety of temperate mountainous ecosystems were resistant to $\mathrm{N}$ addition at different levels and that this microbial resistance more or less depended on the added $\mathrm{N}$ species. Therefore, $\mathrm{N}$ species may work only when the $\mathrm{N}$ load exceeds the threshold of microbial $\mathrm{N}$ resistance in the studied ecosystems. By contrast, we found that the total $\mathrm{CO}_{2}$ emissions were significantly stimulated by an increased temperature (Table 1; Figure 1). This increase, however, may not be due to changes in the soil microbial community size because soil microbial biomass was significantly reduced under a high temperature of $30^{\circ} \mathrm{C}$ (Figure 2). This increase is more likely attributable to temperature-induced changes in the microbial community composition (Wei et al., 2017) and microbial physiology, as indicated by the standardized $\mathrm{CO}_{2}$ emissions by dividing the total amount of PLFAs (Table 1), i.e., the $\mathrm{CO}_{2}$ emissions per unit of soil microbial biomass.

Soil $\mathrm{CO}_{2}$ released during the investigation period was significantly higher in surface soil than in subsurface soil (Table 1; Figure 1), which was accompanied by a consistent pattern of the biomass of soil microbial communities across the soils (Figure 2). Consequently, this pattern produces a significant decomposition-biomass relationship (Figure 4) as expected, suggesting microbial control of SOC decomposition is mainly due to adjusting the biomass of soil microbial communities. Although soil microbial communities were significantly different in surface soil than those in subsurface soil, as presented in our parallel study (Wei et al., 2017), our observations of significant linear regressions with high coefficients of determination (all $R^{2}>0.50$ ) support the hypothesis that the biomass of soil microbial communities may be of primary importance to control SOC decomposition (Fang and Moncrieff, 2005; Colman and Schimel, 2013; Ali et al., 2018), at least in this type of $\mathrm{N}$-rich forest soil. This hypothesis is supported by the significant soil effect on the total $\mathrm{CO}_{2}$ emissions but insignificant effect on the $\mathrm{CO}_{2} /$ PLFAs index (Table 1). This scenario could be attributed to the close correlations between the soil microbial community size and both the enzyme kinetic parameters (e.g., Michaelis constant $K_{\mathrm{m}}$ ) and its catalytic efficiency along with soil depth (Parvin et al., 2018), because microbial activity very likely depends on the enzymatic properties (Conant et al., 2011).

Such a decomposition-biomass relationship should be variable depending on environmental conditions. As observed in the present study, temperature may significantly modify the decomposition-biomass relationship, with significantly higher $\mathrm{C}$ emission potential per unit of soil microbial biomass at high temperatures (Figure 4). The correspondence of the slope index to the metabolic quotient reflects a cell eco-physiological entity and may rapidly respond to environmental stresses (Wardle and Ghani, 1995; Anderson, 2003; Saleem, 2015). Increasing the temperature could result in higher C and energy investments to maintain the stability of microbial cells and then in a higher metabolic quotient as a result of metabolic activation (Alvarez et al., 1995). The changing metabolic activity of soil microbial communities mainly contributed to the increasing trend of the slope index with temperature increases (Figure 4), probably as a result of temperature stimulation of microbial physiology, activity, and C utilization efficiency 
(Schimel et al., 2007; Saleem, 2015), which is associated with the temperature sensitivity of key parameters involved in microbial C processes (Davidson and Janssens, 2006; Wieder et al., 2013). Moreover, soil microbial activity and function may be related to the soil microbial community composition (Wei et al., 2014; Chen et al., 2019), and thus, shifts in the soil microbial community composition among temperature treatments (Wei et al., 2017) may induce modifications in the relationship between the size and function of the soil microbial community.

By contrast, the size of soil microbial communities does not account for the increase in the slope index with temperature (Figure 4) because soil microbial biomass is significantly lower at higher (e.g., $30^{\circ} \mathrm{C}$ ) compared with lower temperatures (Figure 2). The same pattern of reduced soil microbial biomass under warming temperatures has been frequently observed in both field and incubation experiments (Lipson et al., 2000; Frey et al., 2008; Wei et al., 2014). This scenario could be attributable to altered substrate availability and microbial $\mathrm{C}$ assimilation efficiency or self-consumption of soil microbial biomass at high temperatures (Alvarez et al., 1995; Frey et al., 2008; Conant et al., 2011). Finally, warming induced increments in soil $\mathrm{CO}_{2}$ emissions are more likely due to increases in microbial physiological activity, which is supported by the increased $\mathrm{CO}_{2}$ /PLFAs index indicating the activity per unit of soil microorganisms. This change in soil microbial physiological efficiency could be related to the shifts in soil microbial community composition revealed by the PLFAs analysis in our parallel study (Wei et al., 2017).

\section{CONCLUSIONS}

The current $\mathrm{N}$ load did not significantly affect SOC decomposition, regardless of the changed $\mathrm{N}$ species, whereas increased

\section{REFERENCES}

Ali, R. S., Kandeler, E., Marhan, S., Demyan, M. S., Ingwersen, J., Mirzaeitalarposhti, R., et al. (2018). Controls on microbially regulated soil organic carbon decomposition at the regional scale. Soil Biol. Biochem. 118, 59-68. doi: 10.1016/j.soilbio.2017.12.007

Alvarez, R., Santanatoglia, O. J., and Garcîa, R. (1995). Effect of temperature on soil microbial biomass and its metabolic quotient in situ under different tillage systems. Biol. Fertil. Soils 19, 227-230. doi: 10.1007/BF00336164

Anderson, T.-H. (2003). Microbial eco-physiological indicators to asses soil quality. Agric. Ecosyst. Environ. 98, 285-293. doi: 10.1016/ s0167-8809(03)00088-4

Batjes, N. H. (1996). Total carbon and nitrogen in the soils of the world. Eur. J. Soil Sci. 47, 151-163. doi: 10.1111/j.1365-2389.1996.tb01386.x

Birge, H. E., Conant, R. T., Follett, R. F., Haddix, M. L., Morris, S. J., Snapp, S. S., et al. (2015). Soil respiration is not limited by reductions in microbial biomass during long-term soil incubations. Soil Biol. Biochem. 81, 304-310. doi: 10.1016/j.soilbio.2014.11.028

Bond-Lamberty, B., Bailey, V. L., Chen, M., Gough, C. M., and Vargas, R. (2018). Globally rising soil heterotrophic respiration over recent decades. Nature 560, 80-83. doi: 10.1038/s41586-018-0358-x

Bond-Lamberty, B., and Thomson, A. (2010). Temperature-associated increases in the global soil respiration record. Nature 464, 579-582. doi: 10.1038/ nature 08930 temperature significantly stimulated soil microbial activity. The SOC decomposition rate showed a good correlation with the soil microbial community size, as determined by both the fumigation and PLFAs methods. This result suggests that soil microbial communities control SOC decomposition mainly by adjusting the size of microbial communities. However, warming temperatures could significantly affect the decomposition-biomass relationship. Combined with the observed decline in microbial biomass at high temperatures, our results indicate that warminginduced increases in microbial $\mathrm{CO}_{2}$ production are most likely due to altered microbial physiological activity. These results indicate a high dependence of SOC decomposition on the size of the soil microbial community, but this dependence is vulnerable to environmental changes, such as global warming.

\section{AUTHOR CONTRIBUTIONS}

WS and $\mathrm{HW}$ conceived the experiment. $\mathrm{HW}, \mathrm{XC}$, and $\mathrm{JH}$ conducted the study. HW, XC, and LH analyzed the data and wrote the draft manuscript. All authors contributed to result discussion and manuscript revision.

\section{FUNDING}

This study was financed by the National Natural Science Foundation of China (31425005, 31500401, U1701236 and 31400415) and the Guangdong BaiQianWan Talents Program.

\section{ACKNOWLEDGMENTS}

Dr. Zhang W., Ms. Long C. Q., and Ms. Jia Y. X. are acknowledged for their help on soil collection and laboratory analyses.

Bossio, D. A., and Scow, K. M. (1998). Impacts of carbon and flooding on soil microbial communities: phospholipid fatty acid profiles and substrate utilization patterns. Microb. Ecol. 35, 265-278. doi: 10.1007/s002489900082

Chen, H., Li, D., Gurmesa, G. A., Yu, G., Li, L., Zhang, W., et al. (2015). Effects of nitrogen deposition on carbon cycle in terrestrial ecosystems of China: a meta-analysis. Environ. Pollut. 206, 352-360. doi: 10.1016/j. envpol.2015.07.033

Chen, D., Xing, W., Lan, Z., Saleem, M., Wu, Y., Hu, S., et al. (2019). Direct and indirect effects of nitrogen enrichment on soil organisms and carbon and nitrogen mineralization in a semi-arid grassland. Funct. Ecol. 33, 175187. doi: $10.1111 / 1365-2435.13226$

Colman, B. P., and Schimel, J. P. (2013). Drivers of microbial respiration and net N mineralization at the continental scale. Soil Biol. Biochem. 60, 65-76. doi: 10.1016/j.soilbio.2013.01.003

Conant, R. T., Ryan, M. G., Ågren, G. I., Birge, H. E., Davidson, E. A., Eliasson, P. E., et al. (2011). Temperature and soil organic matter decomposition rates - synthesis of current knowledge and a way forward. Glob. Chang. Biol. 17, 3392-3404. doi: 10.1111/j.1365-2486.2011.02496.x

Davidson, E. A., and Janssens, I. A. (2006). Temperature sensitivity of soil carbon decomposition and feedbacks to climate change. Nature 440, 165-173. doi: 10.1038/nature04514

Eberwein, J. R., Oikawa, P. Y., Allsman, L. A., and Jenerette, G. D. (2015). Carbon availability regulates soil respiration response to nitrogen and temperature. Soil Biol. Biochem. 88, 158-164. doi: 10.1016/j.soilbio.2015.05.014 
Eberwein, J., Shen, W., and Jenerette, G. D. (2017). Michaelis-Menten kinetics of soil respiration feedbacks to nitrogen deposition and climate change in subtropical forests. Sci. Rep. 7:1752. doi: 10.1038/s41598-017-01941-8

Fang, Y. T., Gundersen, P., Mo, J. M., and Zhu, W. X. (2008). Input and output of dissolved organic and inorganic nitrogen in subtropical forests of South China under high air pollution. Biogeosciences 5, 339-352. doi: 10.5194/ bg-5-339-2008

Fang, C., Li, F., Pei, J., Ren, J., Gong, Y., Yuan, Z., et al. (2018). Impacts of warming and nitrogen addition on soil autotrophic and heterotrophic respiration in a semi-arid environment. Agric. For. Meteorol. 248, 449-457. doi: 10.1016/j.agrformet.2017.10.032

Fang, C., and Moncrieff, J. B. (2005). The variation of soil microbial respiration with depth in relation to soil carbon composition. Plant Soil 268, 243-253. doi: 10.1007/s11104-004-0278-4

Frey, S. D., Drijber, R., Smith, H., and Melillo, J. (2008). Microbial biomass, functional capacity, and community structure after 12 years of soil warming. Soil Biol. Biochem. 40, 2904-2907. doi: 10.1016/j.soilbio.2008.07.020

Friedlingstein, P., Cox, P., Betts, R., Bopp, L., Von Bloh, W., Brovkin, V., et al. (2010). Climate-carbon cycle feedback analysis: results from the C4MIP model intercomparison. J. Clim. 19, 3337-3353. doi: 10.1175/JCLI3800.1

Galloway, J. N., Townsend, A. R., Erisman, J. W., Bekunda, M., Cai, Z. C., Freney, J. R., et al. (2008). Transformation of the nitrogen cycle: recent trends, questions, and potential solutions. Science 320, 889-892. doi: 10.1126/ science.1136674

Garcia-Palacios, P., Vandegehuchte, M. L., Shaw, E. A., Dam, M., Post, K. H., Ramirez, K. S., et al. (2015). Are there links between responses of soil microbes and ecosystem functioning to elevated $\mathrm{CO}_{2}, \mathrm{~N}$ deposition and warming? A global perspective. Glob. Chang. Biol. 21, 1590-1600. doi: 10.1111/gcb.12788

Gutknecht, J. L. M., Field, C. B., and Balser, T. C. (2012). Microbial communities and their responses to simulated global change fluctuate greatly over multiple years. Glob. Chang. Biol. 18, 2256-2269. doi: 10.1111/j.1365-2486.2012.02686.x

Hararuk, O., Smith, M. J., and Luo, Y. (2015). Microbial models with datadriven parameters predict stronger soil carbon responses to climate change. Glob. Chang. Biol. 21, 2439-2453. doi: 10.1111/gcb.12827

Huang, Y., Guenet, B., Ciais, P., Janssens, I. A., Soong, J. L., Wang, Y., et al. (2018). ORCHIMIC (v1.0), a microbe-mediated model for soil organic matter decomposition. Geosci. Model Dev. 11, 2111-2138. doi: 10.5194/gmd-11-2111-2018

Hunova, I., Kurfurst, P., Stranik, V., and Modlik, M. (2017). Nitrogen deposition to forest ecosystems with focus on its different forms. Sci. Total Environ. 575, 791-798. doi: 10.1016/j.scitotenv.2016.09.140

IPCC (2013). Climate Change 2013: The Physical Science Basis. Contribution of Working Group I to the Fifth Assessment Report of the Intergovernmental Panel on Climate Change. United Kingdom and New York: Cambridge University Press, Cambridge.

Janssens, I. A., Dieleman, W., Luyssaert, S., Subke, J. A., Reichstein, M., Ceulemans, R., et al. (2010). Reduction of forest soil respiration in response to nitrogen deposition. Nat. Geosci. 3, 315-322. doi: 10.1038/ngeo844

Jian, J., Steele, M. K., Thomas, R. Q., Day, S. D., and Hodges, S. C. (2018). Constraining estimates of global soil respiration by quantifying sources of variability. Glob. Chang. Biol. 24, 4143-4159. doi: 10.1111/gcb.14301

Kirschbaum, M. U. F. (2006). The temperature dependence of organic-matter decomposition-still a topic of debate. Soil Biol. Biochem. 38, 2510-2518. doi: $10.1016 /$ j.soilbio.2006.01.030

Lal, R. (2018). Digging deeper: a holistic perspective of factors affecting soil organic carbon sequestration in agroecosystems. Glob. Chang. Biol. 24, 3285-3301. doi: 10.1111/gcb.14054

Lipson, D. A., Schmidt, S. K., and Monson, R. K. (2000). Carbon availability and temperature control the post-snowmelt decline in alpine soil microbial biomass. Soil Biol. Biochem. 32, 441-448. doi: 10.1016/ S0038-0717(99)00068-1

Liu, L. L., and Greaver, T. L. (2010). A global perspective on belowground carbon dynamics under nitrogen enrichment. Ecol. Lett. 13, 819-828. doi: 10.1111/j.1461-0248.2010.01482.x

Liu, X., Zhang, Y., Han, W., Tang, A., Shen, J., Cui, Z., et al. (2013). Enhanced nitrogen deposition over China. Nature 494, 459-462. doi: 10.1038/nature11917

Melillo, J. M., Frey, S. D., DeAngelis, K. M., Werner, W. J., Bernard, M. J., Bowles, F. P., et al. (2017). Long-term pattern and magnitude of soil carbon feedback to the climate system in a warming world. Science 358, 101-105. doi: $10.1126 /$ science.aan 2874
Parvin, S., Blagodatskaya, E., Becker, J. N., Kuzyakov, Y., Uddin, S., and Dorodnikov, M. (2018). Depth rather than microrelief controls microbial biomass and kinetics of C-, N-, P- and S-cycle enzymes in peatland. Geoderma 324, 67-76. doi: 10.1016/j.geoderma.2018.03.006

Ramirez, K. S., Craine, J. M., and Fierer, N. (2010). Nitrogen fertilization inhibits soil microbial respiration regardless of the form of nitrogen applied. Soil Biol. Biochem. 42, 2336-2338. doi: 10.1016/j.soilbio.2010.08.032

Ramirez, K. S., Craine, J. M., and Fierer, N. (2012). Consistent effects of nitrogen amendments on soil microbial communities and processes across biomes. Glob. Chang. Biol. 18, 1918-1927. doi: 10.1111/j.1365-2486.2012.02639.x

Saleem, M. (2015). Microbiome community ecology: Fundamentals and applications. (Switzerland: Springer).

Scharlemann, J. P. W., Tanner, E. V. J., Hiederer, R., and Kapos, V. (2014). Global soil carbon: understanding and managing the largest terrestrial carbon pool. Carbon Management 5, 81-91. doi: 10.4155/Cmt.13.77

Schimel, J., Balser, T. C., and Wallenstein, M. (2007). Microbial stress-response physiology and its implications for ecosystem funtion. Ecology 88, 1386-1394. doi: 10.1890/06-0219

Stewart, C. E., Paustian, K., Conant, R. T., Plante, A. F., and Six, J. (2007). Soil carbon saturation: concept, evidence and evaluation. Biogeochemistry 86, 19-31. doi: 10.1007/s10533-007-9140-0

Stockmann, U., Adams, M. A., Crawford, J. W., Field, D. J., Henakaarchchi, N., Jenkins, M., et al. (2013). The knowns, known unknowns and unknowns of sequestration of soil organic carbon. Agric. Ecosyst. Environ. 164, 80-99. doi: 10.1016/j.agee.2012.10.001

Tang, X., Liu, S., Zhou, G., Zhang, D., and Zhou, C. (2006). Soil-atmospheric exchange of $\mathrm{CO} 2, \mathrm{CH} 4$, and $\mathrm{N} 2 \mathrm{O}$ in three subtropical forest ecosystems in southern China. Glob. Chang. Biol. 12, 546-560. doi: 10.1111/j. 1365-2486.2006.01109.x

Vance, E. D., Brookes, P. C., and Jenkinson, D. (1987). An extraction method for measuring soil microbial biomass C. Soil Biol. Biochem. 19, 703-707. doi: 10.1016/0038-0717(87)90052-6

von Lützow, M., Kögel-Knabner, I., Ekschmitt, K., Matzner, E., Guggenberger, G., Marschner, B., et al. (2006). Stabilization of organic matter in temperate soils: mechanisms and their relevance under different soil conditions-review. Eur. J. Soil Sci. 57, 426-445. doi: 10.1111/j.1365-2389.2006.00809.x

Wang, W. J., Dalal, R. C., Moody, P. W., and Smith, C. J. (2003). Relationships of soil respiration to microbial biomass, substrate availability and clay content. Soil Biol. Biochem. 35, 273-284. doi: 10.1016/S0038-0717(02)00274-2

Wang, Q., Liu, S., Wang, Y., Tian, P., and Sun, T. (2018). Influences of N deposition on soil microbial respiration and its temperature sensitivity depend on $\mathrm{N}$ type in a temperate forest. Agric. For. Meteorol. 260-261, 240-246. doi: 10.1016/j.agrformet.2018.06.018

Wardle, D. A., and Ghani, A. (1995). A critique of the microbial metabolic quotient $(\mathrm{qCO} 2)$ as a bioindicator of disturbance and ecosystem development. Soil Biol. Biochem. 27, 1601-1610. doi: 10.1016/0038-0717(95)00093-T

Wei, H., Chen, X., He, J., Zhang, J., and Shen, W. (2017). Exogenous nitrogen addition reduced the temperature sensitivity of microbial respiration without altering the microbial community composition. Front. Microbiol. 8:2382. doi: 10.3389/fmicb.2017.02382

Wei, H., Chen, X. M., Xiao, G. L., Guenet, B., Vicca, S., and Shen, W. J. (2015). Are variations in heterotrophic soil respiration related to changes in substrate availability and microbial biomass carbon in the subtropical forests? Sci. Rep. 5:18370. doi: 10.1038/srep18370

Wei, H., Guenet, B., Vicca, S., Nunan, N., AbdElgawad, H., Pouteau, V., et al. (2014). Thermal acclimation of organic matter decomposition in an artificial forest soil is related to shifts in microbial community structure. Soil Biol. Biochem. 71, 1-12. doi: 10.1016/j.soilbio.2014.01.003

Wetterstedt, M. J. Å., Persson, T., and Ågren, G. I. (2009). Temperature sensitivity and substrate quality in soil organic matter decomposition: results of an incubation study with three substrates. Glob. Chang. Biol. 16, 1806-1819. doi: $10.1111 / \mathrm{j} .1365-2486.2009 .02112 . \mathrm{x}$

Whitaker, J., Ostle, N., Nottingham, A. T., Ccahuana, A., Salinas, N., Bardgett, R. D., et al. (2014). Microbial community composition explains soil respiration responses to changing carbon inputs along an Andes-to-Amazon elevation gradient. J. Ecol. 102, 1058-1071. doi: 10.1111/1365-2745.12247

Wieder, W. R., Bonan, G. B., and Allison, S. D. (2013). Global soil carbon projections are improved by modelling microbial processes. Nat. Clim. Chang. 3, 909-912. doi: 10.1038/nclimate1951 
Wu, J., Joergensen, R. G., Pommerening, B., Chaussod, R., and Brookes, P. C. (1990). Measurement of soil microbial biomass C by fumigation-extractionan automated procedure. Soil Biol. Biochem. 22, 1167-1169. doi: 10.1016/0038-0717(90)90046-3

Zhou, W., Hui, D., and Shen, W. (2014). Effects of soil moisture on the temperature sensitivity of soil heterotrophic respiration: a laboratory incubation study. PLoS One 9:e92531. doi: 10.1371/journal.pone.0092531

Zhou, X. B., Zhang, Y. M., and Downing, A. (2012). Non-linear response of microbial activity across a gradient of nitrogen addition to a soil from the Gurbantunggut Desert, northwestern China. Soil Biol. Biochem. 47, 67-77. doi: 10.1016/j.soilbio.2011.05.012
Conflict of Interest Statement: The authors declare that the research was conducted in the absence of any commercial or financial relationships that could be construed as a potential conflict of interest.

Copyright (c) 2019 Wei, Chen, He, Huang and Shen. This is an open-access article distributed under the terms of the Creative Commons Attribution License (CC BY). The use, distribution or reproduction in other forums is permitted, provided the original author(s) and the copyright owner(s) are credited and that the original publication in this journal is cited, in accordance with accepted academic practice. No use, distribution or reproduction is permitted which does not comply with these terms. 